\title{
IL-6 and TNF- $\alpha$ salivary levels according to the periodontal status in Portuguese pregnant women
}

\author{
Vanessa Machado ${ }^{\text {Corresp., }}{ }^{1}$, Maria Fernanda Mesquita ${ }^{2}$, Alexandra Bernardo ${ }^{2}$, Ester Casal ${ }^{3}$, Luís Proença ${ }^{2}$, \\ José João Mendes ${ }^{1}$ \\ ${ }^{1}$ Clinical Research Unit, Centro de Investigação Interdisciplinar Egas Moniz, Instituto Universitário Egas Moniz, Monte da Caparica, Portugal \\ 2 Centro de Investigação Interdisciplinar Egas Moniz, Instituto Universitário Egas Moniz, Monte da Caparica, Portugal \\ 3 Obstetrics and gynecology, Hospital Garcia de Orta, Almada, Portugal \\ Corresponding Author: Vanessa Machado \\ Email address: vmachado@egasmoniz.edu.pt
}

Background: Periodontitis is associated with increased concentration of inflammatory markers and saliva has been proposed as a non-invasive diagnostic fluid in oral and systemic diseases. The levels of salivary biomarkers, such as cytokines, could potentially be used to distinguish periodontal healthy individuals from subjects with periodontal disease. The purpose of this study was to characterize the salivary levels of two inflammatory biomarkers associated with periodontitis, interleukin-6 (IL-6) and tumour necrosis factor-alpha (TNF- $\alpha$ ), in order to assess whether these cytokines salivary levels could potentially be used to complement periodontitis pregnant women diagnose. Methods: Forty-four pregnant women were distributed into three groups, according to their periodontal status: healthy, mild/moderate periodontitis and severe periodontitis. Unstimulated saliva was collected and analysis of TNF- $\alpha$ and IL- 6 salivary levels were performed with Immulite ${ }^{\circledR}$. Results: Women with periodontitis exhibited significantly higher levels ( $p=0.001)$ of salivary IL- 6 and TNF- $\alpha$ compared with the healthy group: 25.1 ( \pm 11.2$) \mathrm{pg} / \mathrm{mL}$ vs. $16.3( \pm 5.0) \mathrm{pg} / \mathrm{mL}$ and $29.7( \pm 17.2) \mathrm{pg} / \mathrm{mL}$ vs. $16.2( \pm 7.6) \mathrm{pg} / \mathrm{mL}$, approximately 1.5 and 1.8 times more, respectively. Additionally, cytokines were significantly increased $(p<0.05)$ in severe periodontitis compared to periodontal healthy pregnant women. Conclusions: These results revealed that IL- 6 and TNF- $\alpha$ salivary biomarkers provide high discriminatory capacity for distinguishing periodontal disease from periodontal health, in pregnant women. 
$1 \quad$ IL- 6 and TNF- $\alpha$ salivary levels according to the periodontal status in

2

3

4

5

6

7

8

Portuguese pregnant women

\section{ABSTRACT}

Background: Periodontitis is associated with increased concentration of inflammatory markers and saliva has been proposed as a non-invasive diagnostic fluid in oral and systemic diseases. The levels of salivary biomarkers, such as cytokines, could potentially be used to distinguish periodontal healthy individuals from subjects with periodontal disease. The purpose of this study was to characterize the salivary levels of two inflammatory biomarkers associated with periodontitis, interleukin-6 (IL-6) and tumour necrosis factor-alpha (TNF- $\alpha$ ), in order to assess whether these cytokines salivary levels could potentially be used to complement periodontitis pregnant women diagnose.

Methods: Forty-four pregnant women were distributed into three groups, according to their periodontal status: healthy, mild/moderate periodontitis and severe periodontitis. Unstimulated saliva was collected and analysis of TNF- $\alpha$ and IL- 6 salivary levels were performed with Immulite ${ }^{\circledR}$.

Results: Women with periodontitis exhibited significantly higher levels ( $p=0.001)$ of salivary IL6 and TNF- $\alpha$ compared with the healthy group: $25.1( \pm 11.2) \mathrm{pg} / \mathrm{mL}$ vs. $16.3( \pm 5.0) \mathrm{pg} / \mathrm{mL}$ and 29.7 $( \pm 17.2) \mathrm{pg} / \mathrm{mL}$ vs. $16.2( \pm 7.6) \mathrm{pg} / \mathrm{mL}$, approximately 1.5 and 1.8 times more, respectively. Additionally, cytokines were significantly increased $(p<0.05)$ in severe periodontitis compared to periodontal healthy pregnant women.

Conclusions: These results revealed that IL-6 and TNF- $\alpha$ salivary biomarkers provide high discriminatory capacity for distinguishing periodontal disease from periodontal health, in pregnant women.

\section{INTRODUCTION}

Periodontal diseases continue to be a major public health problem worldwide, but there is evidence that the initiation, progression and severity does not affect all people in the same way (Dye, 2012; Petersen \& Ogawa, 2012; Baelum \& López, 2013; Persson, 2017). Some epidemiological studies have demonstrated that gingival inflammation affects 60 to $75 \%$ of pregnant women (Löe \& Silness, 1963; Silness \& Löe, 1964; Tilakaratne et al., 2000; Michalowicz et al., 2008; Ho \& Chou, 2016), although not all present the same gingival inflammatory pattern and the symptoms can range from mild inflammation to severe hyperplasia, pain and profuse bleeding. 
36

37

38

39

40

41

42

43

44

45

46

47

48

49

50

51

52

53

54

55

56

57

58

59

60

61

62

63

64

65

66

67

68

69

70

There is evidence that support a causal relationship between inflammation and spontaneous preterm labour (Romero et al., 2006), but the exact etiology of pregnancy gingivitis is still unknown. Some studies demonstrate that the increase of female sexual hormones' serum concentration during gestation, may lead to gingivitis gestation (Brabin, 1985; Gürsoy et al., 2010). Further, host immune and inflammatory responses play a major role in periodontitis (González-Jaranay et al., 2017) and some cytokines genes were suggested to influence the development of periodontal disease (D'Aiuto et al., 2004; Ebersole et al., 2016; Kinane, Stathopoulou \& Papapanou, 2017). Also, when compared to healthy patients, subjects with gingivitis or periodontitis produce high levels of inflammatory mediators, such as IL- 6 and TNF- $\alpha$ (Zhu et al., 2016).

Saliva, as a pooled sample, contains specific biomarkers for unique pathological aspects of

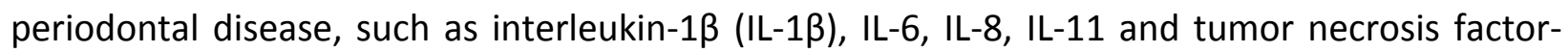
alpha (TNF- $\alpha$ ) (Graves, 2008; Rathnayake et al., 2017). Recent studies suggested that cytokine levels in this fluid might be linked with the periodontal status of the patient (Jaedicke, Preshaw \& Taylor, 2016; Belstrøm et al., 2017). Thus, qualitative changes in the levels of these biomarkers could have diagnostic and therapeutic significance. Interleukin 6 (IL-6) is a pro-inflammatory cytokine associated with the severity of periodontitis contributing to bone resorption (Moreira et al., 2007; Graves, 2008; Jaedicke, Preshaw \& Taylor, 2016; Zhu et al., 2016). TNF- $\alpha$ is a proinflammatory cytokine that has an effect in the activation of inflammatory leukocytes, modification of vascular permeability and induction of bone resorption (Assuma et al., 1998; Varghese et al., 2015) and is a main inducer of IL-6 (Katz, Nadiv \& Beer, 2001).

In the past, some studies demonstrated a correlation between IL- 6 and TNF- $\alpha$ with periodontal status of pregnant women in crevicular fluid and gingival tissue (Carrillo-De-Albornoz et al., 2012; Otenio et al., 2012; Wu et al., 2016). However, there are no investigations concerning the salivary levels of these biomarkers in pregnant women. Therefore, the goal of this pilot investigation was to assess the salivary concentration of IL- 6 and TNF- $\alpha$, according to the periodontal status, in a sample of Portuguese pregnant women.

\section{MATERIALS AND METHODS}

\section{Ethical considerations}

This study was approved by a Portuguese state recognized Ethics Committee, from Garcia de Orta Hospital (Ethical Application Ref: 06/2015) and was carried out in accordance with the Helsinki Declaration of 1975 as revised in 2013. A written informed consent was obtained from all participants prior to appointment. All data were registered on a database specifically created for 
71 this purpose, where a coded number was attributed to each participant. This was a cross72 sectional study without study-defined medical or dental interventions. Patients with diagnosed 73 pathological conditions were referred to receive appropriate treatment.

75

76 77

78

79

80

81

82

83

84

85

86

87

88

89

90

91

92

93

94

95

96

97

98

99

100

101

102

\section{Patient selection}

This pilot study was conducted at the Obstetrics and Gynecology Departments of Garcia de Orta Hospital (Almada, Portugal) over one month period (February 2015). Out of the 408 pregnant women that were being attended at those Departments, 82 (20\%) were randomly selected to participate. From those, taking into account the exclusion criteria, 44 (10.8\% of total) were enrolled in the study. Exclusion criteria were women with congenital uterine and/or vaginal malformations, fetal malformation, multifetal gestation, chronic diseases (e.g., diabetes, hypertension, epilepsy, cardiac disease, lung disease, renal disease, positive test for human immunodeficiency virus (HIV)), history of systemic antibiotic treatment or dental prophylaxis in the previous six months, and using systemic or topical antimicrobial and/or anti-inflammatory therapy within the previous three months and smoking habit. None of the women had received periodontal therapy before and during pregnancy.

\section{Questionnaire}

All women answered a questionnaire, to obtain information about their sociodemographic status (age, marital status, education level, and occupation) and their personal oral hygiene habits (frequency of tooth brushing and dental floss usage).

Educational level was assessed in two categories: basic/middle (1-12 years) and higher (> 12 years). Employment status of each participant was classified as: employed or unemployed. Oral hygiene habits were assessed by information about toothbrush frequency (one time daily, two or more times daily) and dental flossing.

\section{TNF- $\alpha$ and IL-6 measurement in saliva}

Unstimulated saliva samples were collected, by passive drooling, in a Falcon ${ }^{\circledR}$ tube for 2 minutes, between 9:00am and 11:00am. Samples were frozen at the collection day and stored at -80 $9 \mathrm{C}$ until further analysis. The quantifications in whole unstimulated saliva were performed according to Immulite ${ }^{\circledR}$ (Siemens, Germany) manufacturer's protocol and assessed by a duplicate of each sample analyte. Both TNF- $\alpha$ and IL-6 were detected in all samples. IL- 6 and TNF- $\alpha$ levels were expressed in $\mathrm{pg} / \mathrm{mL}$. 
105

Each subject, who accepted to participate in the study, was assessed by an experienced and calibrated examiner. Clinical examination was performed using a headlight with the individuals seated on a regular chair in Garcia de Orta Hospital and required, on average, 45 min, without radiographic examination.

Periodontitis was defined as severe (individuals with $\geq 2$ interproximal sites with clinical attachment loss $(C A L) \geq 6 \mathrm{~mm}$, not on the same tooth and $\geq 1$ interproximal sites with probing depth (PD) $\geq 5 \mathrm{~mm}$ ), moderate (individuals with $\geq 2$ interproximal sites with CAL $\geq 4 \mathrm{~mm}$, not on the same tooth or $\geq 2$ interproximal sites with PD $\geq 5 \mathrm{~mm}$, not on the same tooth) and mild ( $\geq 2$ interproximal sites with CAL $\geq 3 \mathrm{~mm}$, and $\geq 2$ interproximal sites with $\mathrm{PD} \geq 4 \mathrm{~mm}$ or one site with $P D \geq 5 \mathrm{~mm}$ ) (Page \& Eke, 2007).

\section{Data analysis}

Data analysis was performed using IBM SPSS Statistics version 24.0 for Windows (Armonk, NY: IBM Corp.). Descriptive statistics as frequencies, means and standard deviations were calculated. Population means were estimated by calculating $95 \%$ confidence intervals ( $95 \% \mathrm{Cl})$. Inferential statistics methodologies (t-Student's and ANOVA with Brown-Forsythe correction tests) were used to compare both TNF- $\alpha$ and IL- 6 data as a function of the periodontal status. The level of significance was set at $5 \%$.

\section{RESULTS}

The patient's characteristics, according to the periodontal diagnosis, are shown in Tables 1 to 3. No significant differences were found in socio-demographic and oral health behaviour characteristics among the groups. In total, mean age was 32.4 years ( \pm 5.5 ) (range, $15-43$ years) and the average gestation period was 25.4 weeks (range, 6-41 weeks). The majority were in the second (43.2\%) and third trimesters (40.9\%) of pregnancy, and only $15.9 \%$ were in the firsttrimester.

Moreover, the education level showed similar numbers among healthy ones, but the majority of pregnant women with mild/moderate or severe periodontitis had basic/middle $(81.2 \%, 61.5 \%$ respectively) education levels. The majority of participants were employed (65.1\%) and married $(72.7 \%)$. Concerning the attitude and behaviour of pregnant women, $86.4 \%$ participants $(n=38)$ 
135 brushed their teeth twice or more a day and 68.2\% were not using interdental brushes and dental 136 floss.

137 The observed prevalence of periodontitis was $65.9 \%$ (95\% Cl, $52.6-79.1 \%)$. Specifically, the prevalence of mild/moderate and severe periodontitis was $36.4 \%$ (95\% Cl, $23.0-49.8 \%$ ) and $29.5 \%(95 \% \mathrm{Cl}, 16.8-42.2 \%)$, respectively.

140 Descriptive statistics (mean and standard deviation) and 95\% Cl for means, of IL-6 and TNF- $\alpha$, for healthy and periodontitis groups, were calculated and are displayed in Table 2. Mean salivary

142 levels of IL- 6 and TNF- $\alpha$ were significantly higher $(p=0.001)$ in subjects with periodontitis than in 143 healthy subjects: 25.1 ( \pm 11.2$)$ vs. $16.3( \pm 5.0) \mathrm{pg} / \mathrm{mL}$ and $29.7( \pm 17.2)$ vs. $16.2( \pm 7.6) \mathrm{pg} / \mathrm{mL}$, approximately 1.5 times and 1.8 times more, respectively.

Cytokine concentrations were significantly different between the healthy and different periodontal status groups (Table 3 ). Salivary levels of IL-6 and TNF- $\alpha$ were significantly increased $(p<0.05)$ in severe periodontitis compared to periodontal healthy group, but were not found to be statistically significant among periodontitis groups.

149

150

\section{DISCUSSION}

The purpose of this pilot study was to evaluate salivary levels of IL- 6 and TNF- $\alpha$ according to periodontal status in pregnant women, in order to assess if the level of these pro-inflammatory cytokines could potentially be used as complementary diagnostic in pregnant women with periodontitis. The main finding was that periodontitis was associated with a significant increase in salivary concentrations of all cytokines investigated when compared with periodontal health pregnant women.

158

159

160

161

162

163

164

165

166

167

This cross-sectional pilot study assessed the periodontal status of forwarded pregnant women subjects who were attended at Obstetrics and Gynecology Departments of Garcia de Orta Hospital, that is located in the metropolitan area of Lisbon. To the best of our knowledge, this is the first investigation that associated periodontal status and cytokines levels in a Portuguese women pregnant population.

Although our findings are somewhat limited by the small sample size and for being a crosssectional study, the selection criteria were very narrow and served to avoid potential influence on cytokines levels, thus increasing the strength of the results. Furthermore, it doesn't provide temporal relationship between exposure and outcome. Thus, in the future we intend to perform a longitudinal study to clarify the periodontal effect and complications on pregnancy. 
168 Traditionally, periodontal diagnosis criteria includes plaque index, gingival index, clinical

169

170

171

172

173

174

175

176

177

178

179

180

181

182

183

184

185

186

187

188

189

190

191

192

193

194

195

196

197

198

199

200

201 attachment levels, probing depths, bleeding on probing, mobility of teeth, furcation involvement and radiographic analysis (Page et al., 1997; Eke et al., 2015). However, pregnant women are not recommended to do radiographic analysis and the diagnosis with these criteria takes a long time. Additionally, these diagnostic parameters are excellent on determining a past history of periodontal disease, however they do not evaluate the inflammatory pattern of the ongoing disease and it is not possible to detect its onset or progression. Saliva represents from whole mouth with all periodontal sites, thereby giving a general assessment of periodontal disease. Thus, salivary cytokine levels have the potential to reflect current activity, disease severity and possibly predict future disease progression, and make aware of immediate or future treatment needs (Kaufman \& Lamster, 2000; Prasad, Tyagi \& Aggarwal, 2015; Jaedicke, Preshaw \& Taylor, 2016; Korte \& Kinney, 2016; Morand et al., 2017).

In this investigation, the periodontitis group showed higher salivary levels of IL-6 and TNF- $\alpha$ compared with periodontal healthy pregnant women. In detail, IL- 6 and TNF- $\alpha$ were only significantly increased in severe periodontitis compared to periodontal healthy groups. Moreover, there were differences between mild/moderate and severe periodontitis. These data are in accordance with previous findings where IL-6 and TNF- $\alpha$ salivary concentrations were significantly elevated in periodontitis patients (Taba Jr et al., 2005; Miller et al., 2006; Scannapieco et al., 2007; Frodge et al., 2008; Giannobile et al., 2009; Ebersole et al., 2013). According to our results, IL-6 and TNF- $\alpha$ salivary levels appears to have potential to distinguish pregnant women with and without periodontal disease.

\section{CONCLUSIONS}

Periodontal compromised pregnant women showed significantly higher IL- 6 and TNF- $\alpha$ salivary levels than healthy ones. These salivary biomarkers are likely to provide great clinical benefit when supplemented with other clinical information. More studies are needed with longitudinal methodology and larger samples to provide validated reference values that distinguish periodontal disease from periodontal health, especially in initial and developing phases, in order to predict the appearance and estimate the future disease progress during pregnancy.

\section{Acknowledgements}


202 The authors declare no financial or commercial conflict of interest. This work was supported by 203 Egas Moniz - Cooperativa de Ensino Superior (Egas Moniz, CRL) and CiiEM Biochemistry 204 Laboratory (BioquiLab).

205

206

207

208

209

210

211

212

213

214

215

216

217

218

219

220

221

222

223

224

225

226

227

228

229

230

231

232

233

234

235

236

237

238

239

\section{REFERENCES}

Assuma R., Oates T., Cochran D., Amar S., Graves DT. 1998. IL-1 and TNF antagonists inhibit the inflammatory response and bone loss in experimental periodontitis. Journal of immunology 160:403-409. DOI: papers3://publication/uuid/9E057C99-203D-4E869CE9-50389CCCF767.

Baelum V., López R. 2013. Periodontal disease epidemiology - learned and unlearned? Periodontology 2000 62:37-58. DOI: 10.1111/j.1600-0757.2012.00449.x.

Belstrøm D., Damgaard C., Könönen E., Gürsoy M., Holmstrup P., Gürsoy UK. 2017. Salivary cytokine levels in early gingival inflammation. Journal of Oral Microbiology 9:1364101. DOI: 10.1080/20002297.2017.1364101.

Brabin B. 1985. Epidemiology of infection in Pregnancy. Reviews of Infectious Disease 7:579-603.

Carrillo-De-Albornoz A., Figuero E., Herrera D., Cuesta P., Bascones-Martínez A. 2012. Gingival changes during pregnancy: III. Impact of clinical, microbiological, immunological and socio-demographic factors on gingival inflammation. Journal of Clinical Periodontology 39:272-283. DOI: 10.1111/j.1600-051X.2011.01800.x.

D'Aiuto F., Parkar M., Andreou G., Suvan J., Brett PM., Ready D., Tonetti MS. 2004. Periodontitis and systemic inflammation: control of the local infection is associated with a reduction in serum inflammatory markers. Journal of Dental Research 83:156160.

Dye BA. 2012. Global periodontal disease epidemiology. Periodontology 2000 58:10-25. DOI: 10.1111/j.1600-0757.2011.00413.x.

Ebersole JL., Graves CL., Gonzalez OA., Dowson III D., Morford LA., Huja PE., Hartsfield Jr JK., Huja SS., Pandruvada S., Wallet SM. 2016. Aging , in fl ammation , immunity and periodontal disease. Periodontology 2000 72:54-75.

Ebersole JL., Schuster JL., Stevens J., Dawson D., Kryscio RJ., Lin Y., Thomas M V., Miller CS. 2013. Patterns of salivary analytes provide diagnostic capacity for distinguishing chronic adult periodontitis from health. Journal of Clinical Immunology 33:271-279. DOI: 10.1007/s10875-012-9771-3.

Eke PI., Dye BA., Wei L., Slade GD., Thornton-Evans GO., Borgnakke WS., Taylor GW., Page RC., Beck JD., Genco RJ. 2015. Update on Prevalence of Periodontitis in Adults in the United States: NHANES 2009 - 2012. Journal of Periodontology:1-18. DOI: 10.1902/jop.2015.140520. 
240

241

242

243

244

Frodge BD., Ebersole JL., Kryscio RJ., Thomas M V., Miller CS. 2008. Bone remodeling biomarkers of periodontal disease in saliva. Journal of periodontology 79:1913-1919. DOI: 10.1902/jop.2008.080070.

Giannobile W V., Beikler T., Kinney JS., Ramseier C a., Morelli T., Wong DT. 2009. Saliva as a diagnostic tool for periodontal disease: Current state and future directions. Periodontology 2000 50:52-64. DOI: 10.1111/j.1600-0757.2008.00288.x. González-Jaranay M., Téllez L., Roa-López A., Gómez-Moreno G., Moreu G. 2017. Periodontal status during pregnancy and postpartum. PLOS ONE 12:1-9. DOI: 10.1371/journal.pone.0178234.

Graves D. 2008. Cytokines that promote periodontal tissue destruction. Journal of periodontology 79:1585-1591. DOI: 10.1902/jop.2008.080183.

Gürsoy M., Könönen E., Tervahartiala T., Gürsoy UK., Pajukanta R., Sorsa T. 2010. Longitudinal study of salivary proteinases during pregnancy and postpartum. Journal of Periodontal Research 45:496-503. DOI: 10.1111/j.1600-0765.2009.01264.x. Ho CC., Chou MY. 2016. Periodontal status in Taiwanese pregnant women. Journal of Dental Sciences 11:146-151. DOI: 10.1016/j.jds.2016.03.007.

Jaedicke KM., Preshaw PM., Taylor JJ. 2016. Salivary cytokines as biomarkers of periodontal diseases. Periodontology 2000 70:164-183. DOI: 10.1111/prd.12117.

Katz Y., Nadiv O., Beer Y. 2001. Interleukin-17 Enhances Tumor Necrosis Factor alphaInduced Synthesis of Interleukins 1, 6, and 8 in Skin and Synovial Fibroblasts. Arthristis \& Rheumatism 44:2176-2184. DOI: 10.1002/1529-0131(200109)44:9<2176::AIDART371>3.0.CO;2-4.

Kaufman E., Lamster I. B. 2000. Analysis of saliva for periodontal diagnosis--a review. Journal of clinical periodontology 27:453-465. DOI: 10.1034/j.1600051x.2000.027007453.x.

Kinane DF., Stathopoulou PG., Papapanou PN. 2017. Periodontal diseases. Nature Reviews Disease Primers 3:1-14. DOI: 10.1038/nrdp.2017.38.

Korte DL., Kinney J. 2016. Personalized medicine: An update of salivary biomarkers for periodontal diseases. Periodontology 2000 70:26-37. DOI: 10.1111/prd.12103.

Loe H., Silness J. 1963. Periodontal disease in pregnancy - I.Prevalence and severity. Acta odontologica scandinavica 21:533-551. DOI: 10.3109/00016356309011240.

Michalowicz BS., Diangells AJ., John Novak M., Buchanan W., Papapanou PN., Mitchell DA., Curran AE., Lupo VR., Ferguson JE., Bofill J., Matseoane S., Deinard AS., Rogers TB. 2008. Examining the safety of dental treatment in pregnant women. Journal of the American Dental Association 139:685-695. DOI: 10.14219/jada.archive.2008.0250. Miller CS., King CP., Langub MC., Kryscio RJ., Thomas M V. 2006. Salivary biomarkers of existing periodontal disease. The Journal of the American Dental Association 137:322329. DOI: 10.14219/jada.archive.2006.0181. 
278

279

280

281

282

283

284

285

286

287

288

289

290

291

292

293

294

295

296

297

298

299

300

301

302

303

304

305

306

307

308

309

310

311

312

313

314

315

Morand D., Davideau J-L., Clauss F., Jessel N., Tenenbaum H., Huck O. 2017. Cytokines during periodontal wound healing: potential application for new therapeutic approach. Oral Diseases 23:300-311. DOI: 10.1111/odi.12469.

Moreira PR., Lima PMA., Sathler KOB., Imanishi SAW., Costa JE., Gomez RS., Gollob KJ., Dutra WO. 2007. Interleukin- 6 expression and gene polymorphism are associated with severity of periodontal disease in a sample of Brazilian individuals. Clinical and Experimental Immunology 148:119-126. DOI: 10.1111/j.1365-2249.2007.03327.x.

Otenio CC., Fonseca I., Martins MF., Ribeiro LC., Assis NM., Ferreira AP., Ribeiro RA. 2012. Expression of IL-1 $\beta$, IL-6, TNF- $\alpha$, and iNOS in pregnant women with periodontal disease. Genetics and molecular research : GMR 11:4468-4478. DOI: 10.4238/2012.September.20.3.

Page RC., Eke PI. 2007. Case Definitions for Use in Population-Based Surveillance of Periodontitis. Journal of Periodontology 78:1387-1399. DOI:

10.1902/jop.2007.060264.

Page RC., Offenbacher S., Schroeder HE., Seymour GJ., Kornman KS. 1997. Advances in the pathogenesis of periodontitis: summary of developments, clinical implications and future directions. Periodontology 2000 14:216-248. DOI: 10.1111/j.16000757.1997.tb00199.x.

Persson GR. 2017. Dental geriatrics and periodontitis. Periodontology 2000 74:102-115. DOI: $10.1111 /$ prd.12192.

Petersen PE., Ogawa H. 2012. The global burden of periodontal disease: Towards integration with chronic disease prevention and control. Periodontology 2000 60:1539. DOI: 10.1111/j.1600-0757.2011.00425.x.

Prasad S., Tyagi AK., Aggarwal BB. 2015. Detection of inflammatory biomarkers in saliva and urine: Potential in diagnosis, prevention, and treatment for chronic diseases. Experimental Biology and Medicine 241:783-799. DOI: 10.1177/1535370216638770. Rathnayake N., Gieselmann D-R., Heikkinen A., Tervahartiala T., Sorsa T. 2017. Salivary Diagnostics-Point-of-Care diagnostics of MMP-8 in dentistry and medicine.

Diagnostics 7:7. DOI: 10.3390/diagnostics7010007.

Romero R., Espinoza J., Kusanovic JP., Gotsch F., Hassan S., Erez O., Chaiworapongsa T., Mazor M. 2006. The preterm parturition syndrome. BJOG: An International Journal of Obstetrics and Gynaecology 113:17-42. DOI: 10.1111/j.1471-0528.2006.01120.x. Scannapieco F a., Ng P., Hovey K., Hausmann E., Hutson a., Wactawski-Wende J. 2007. Salivary biomarkers associated with alveolar bone loss. Annals of the New York Academy of Sciences 1098:496-497. DOI: 10.1196/annals.1384.034.

Silness J., Löe H. 1964. Periodontal disease in pregnancy II. Correlation between oral hygiene and periodontal condition. Acta odontologica scandinavica 21:121-135. DOI: http://dx.doi.org/10.3109/00016356408993968. 
316

317

318

319

320

321

322

323

324

325

326

327

328

329

330

331

332

333

334

335

Taba Jr M., Kinney J., Kim AS., Giannobile W V. 2005. Diagnostic Biomarkers for oral and periodontal diseases. Dental Clinics of North America 49:551-571. DOI: 10.1016/j.cden.2005.03.009.Diagnostic.

Tilakaratne a., Soory M., Ranasinghe a W., Corea SM., Ekanayake SL., de Silva M. 2000. Periodontal disease status during pregnancy and 3 months post-partum, in a rural population of Sri-Lankan women. Journal of clinical periodontology 27:787-792. DOI: 10.1034/j.1600-051x.2000.027010787.x.

Varghese SS., Thomas H., Jayakumar ND., Sankari M., Lakshmanan R. 2015. Estimation of salivary tumor necrosis factor-alpha in chronic and aggressive periodontitis patients. Contemporary clinical dentistry 6:152-156. DOI: 10.4103/0976-237X.166816.

Wu M., Chen S-W., Su W-L., Zhu H-Y., Ouyang S-Y., Cao Y-T., Jiang S-Y. 2016. Sex Hormones Enhance Gingival Inflammation without Affecting IL-1 $\beta$ and TNF- $\alpha$ in Periodontally Healthy Women during Pregnancy. Mediators of Inflammation 2016:1-6. DOI: 10.1155/2016/4897890.

Zhu J., Guo B., Fu M., Guo W., Yuan Y., Yuan H., Zhang S., Yu H. 2016. Interleukin-6-174G/C Polymorphism Contributes to Periodontitis Susceptibility: An Updated Meta-Analysis of 21 Case-Control Studies. Disease Markers:1-13. DOI: 10.1155/2016/9612421. 


\section{Table $\mathbf{1}$ (on next page)}

Socio-demographic characteristics and oral health behaviors of subjects according to their periodontal status. 


\begin{tabular}{|c|c|c|c|c|c|c|}
\hline & \multicolumn{2}{|c|}{$\begin{array}{l}\text { Healthy } \\
(n=15)\end{array}$} & \multicolumn{2}{|c|}{$\begin{array}{c}\text { Mild/Moderate } \\
\text { Periodontitis } \\
\quad(n=16)\end{array}$} & \multicolumn{2}{|c|}{$\begin{array}{l}\text { Severe Periodontitis } \\
\qquad(n=13)\end{array}$} \\
\hline & $\mathrm{n}$ & $\%$ & $n$ & $\%$ & $\mathrm{n}$ & $\%$ \\
\hline \multicolumn{7}{|l|}{ Education level } \\
\hline Basic/Middle & 8 & 53.3 & 13 & 81.2 & 8 & 61.5 \\
\hline Higher & 7 & 46.7 & 3 & 18.8 & 5 & 38.5 \\
\hline \multicolumn{7}{|l|}{ Marital status } \\
\hline Married & 11 & 73.3 & 13 & 81.2 & 8 & 61.5 \\
\hline Single & 4 & 26.7 & 3 & 18.8 & 5 & 38.5 \\
\hline \multicolumn{7}{|l|}{ Occupation } \\
\hline Employed & 9 & 60.0 & 11 & 68.8 & 9 & 69.2 \\
\hline Unemployed & 6 & 40.0 & 5 & 31.2 & 4 & 30.8 \\
\hline \multicolumn{7}{|l|}{ Toothbrush frequency } \\
\hline One time daily & 1 & 6.7 & 3 & 18.8 & 2 & 13.6 \\
\hline $\begin{array}{l}\text { Two or more times } \\
\text { daily }\end{array}$ & 14 & 93.3 & 13 & 81.2 & 11 & 86.4 \\
\hline \multicolumn{7}{|l|}{ Dental floss usage } \\
\hline Yes & 7 & 46.7 & 4 & 25.0 & 3 & 23.1 \\
\hline No & 8 & 53.3 & 12 & 75.0 & 10 & 76.9 \\
\hline
\end{tabular}




\section{Table 2 (on next page)}

Distribution of cytokines salivary levels $(\mathrm{pg} / \mathrm{ml})$, presented as mean ( \pm standard deviation) and $95 \% \mathrm{Cl}$ for mean, for healthy and periodontitis subjects. 


\begin{tabular}{|c|c|c|c|c|c|}
\hline \multirow{2}{*}{$\begin{array}{c}\text { Inflammatory } \\
\text { cytokines }\end{array}$} & \multicolumn{2}{|c|}{$\begin{array}{c}\text { Healthy } \\
(\mathrm{n}=15)\end{array}$} & \multicolumn{2}{c|}{$\begin{array}{c}\text { Periodontitis } \\
(\mathrm{n}=29)\end{array}$} & \multirow{2}{*}{ * $^{*}$} \\
\cline { 2 - 6 }$(\mathrm{pg} / \mathrm{mL})$ & Mean $( \pm \mathrm{SD})$ & $95 \% \mathrm{Cl}$ & Mean $( \pm \mathrm{SD})$ & $95 \% \mathrm{Cl}$ & \\
\hline TNF- $\alpha$ & $16.3( \pm 5.0)$ & {$[13.5-19.1]$} & $25.1( \pm 11.2)$ & {$[20.9-29.4]$} & 0.001 \\
\hline IL-6 & $16.2( \pm 7.6)$ & {$[12.0-20.5]$} & $29.7( \pm 17.2)$ & {$[23.2-36.3]$} & 0.001 \\
\hline
\end{tabular}

$1 \quad *$ t-Student test

2 


\section{Table 3(on next page)}

Distribution of cytokines salivary levels $(\mathrm{pg} / \mathrm{ml})$, presented as mean ( \pm standard deviation) and $95 \% \mathrm{Cl}$ for mean, for healthy, mild/moderate and severe periodontitis groups. 
1

\begin{tabular}{|c|c|c|c|c|c|c|c|}
\hline $\begin{array}{l}\text { Inflammat } \\
\text { ory } \\
\text { cytokines }\end{array}$ & \multicolumn{2}{|c|}{$\begin{array}{l}\text { Healthy } \\
(n=15)\end{array}$} & \multicolumn{2}{|c|}{$\begin{array}{l}\text { Mild/Moderate } \\
\text { Periodontitis } \\
\quad(n=16)\end{array}$} & \multicolumn{2}{|c|}{$\begin{array}{l}\text { Severe Periodontitis } \\
\qquad(n=13)\end{array}$} & $p^{*}$ \\
\hline$(\mathrm{pg} / \mathrm{mL})$ & $\begin{array}{l}\text { Mean } \\
( \pm S D)\end{array}$ & $95 \% \mathrm{Cl}$ & Mean ( $\pm S D)$ & $95 \% \mathrm{Cl}$ & $\begin{array}{l}\text { Mean } \\
( \pm S D)\end{array}$ & $95 \% \mathrm{Cl}$ & \\
\hline TNF- $\alpha$ & $\begin{array}{c}16.3 \\
( \pm 5.0)^{\mathrm{a}}\end{array}$ & $\begin{array}{l}{[13.5-} \\
19.1]\end{array}$ & $\begin{array}{c}24.3( \pm 12.5) \\
a b\end{array}$ & $\begin{array}{l}{[17.6-} \\
30.9]\end{array}$ & $\begin{array}{c}26.2( \pm 9.6) \\
b\end{array}$ & $\begin{array}{l}{[20.4-} \\
32.0]\end{array}$ & 0.020 \\
\hline IL-6 & $\begin{array}{c}16.2 \\
( \pm 7.6)^{a}\end{array}$ & $\begin{array}{l}{[12.0-} \\
20.5]\end{array}$ & $\begin{array}{c}27.1( \pm 18.4) \\
a b\end{array}$ & $\begin{array}{l}{[17.3-} \\
36.9]\end{array}$ & $\begin{array}{c}33.0 \\
( \pm 15.8)^{b}\end{array}$ & $\begin{array}{l}{[23.4-} \\
42.5]\end{array}$ & 0.016 \\
\hline
\end{tabular}

2 *ANOVA with Brown-Forsythe correction. Different lower case letters indicate significant 3 differences between means in the same row (Games-Howell post-hoc test, $p<0.05$ ) 4 